\title{
Corrigendum
}

\section{Corrigendum to “Instructors' Perceptions of Mostly Seated Exercise Classes: Exploring the Concept of Chair Based Exercise"}

\author{
Katie R. Robinson, ${ }^{1,2}$ Tahir Masud, ${ }^{3}$ and Helen Hawley-Hague ${ }^{4}$ \\ ${ }^{1}$ Division of Rehabilitation and Ageing, University of Nottingham, Queen's Medical Centre, Nottingham NG7 2UH, UK \\ ${ }^{2}$ Bassetlaw Health Partnership, Nottinghamshire Healthcare NHS Foundation Trust, Day Rehabilitation, Retford Primary Care Centre, \\ North Road, Retford DN22 7XF, UK \\ ${ }^{3}$ Healthcare of Older People, Nottingham University Hospitals NHS Trust, Queen's Medical Centre, Nottingham NG7 2UH, UK \\ ${ }^{4}$ Nursing, Midwifery and Social Work, The University of Manchester, Jean McFarlane Building, Floor 6, Room 332, Oxford Road, \\ Manchester M13 9PL, UK
}

Correspondence should be addressed to Helen Hawley-Hague; helen.hawley-hague@manchester.ac.uk

Received 19 January 2017; Accepted 19 February 2017; Published 14 May 2017

Copyright (c) 2017 Katie R. Robinson et al. This is an open access article distributed under the Creative Commons Attribution License, which permits unrestricted use, distribution, and reproduction in any medium, provided the original work is properly cited.

In the article titled "Instructors' Perceptions of Mostly Seated Exercise Classes: Exploring the Concept of Chair Based Exercise" [1], there was an error in the Acknowledgments, which should be corrected as follows:

This work was supported by the Medical Research Council (MRC) Doctoral Training Grant (Grant no. MR/K500823/ 1) and the University of Manchester through the Faculty of Medical and Human Sciences. The authors would also like to thank Professor Dawn Skelton for her advice and Professor Chris Todd, Professor Skelton, and Dr. Maria Horne for their involvement in the original survey design.

\section{References}

[1] K. R. Robinson, T. Masud, and H. Hawley-Hague, "Instructors' perceptions of mostly seated exercise classes: exploring the concept of chair based exercise," BioMed Research International, vol. 2016, Article ID 3241873, 8 pages, 2016. 


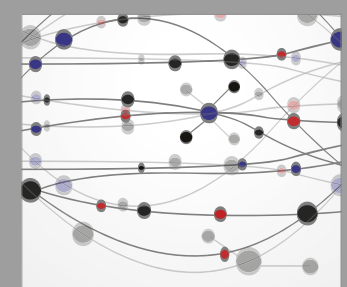

The Scientific World Journal


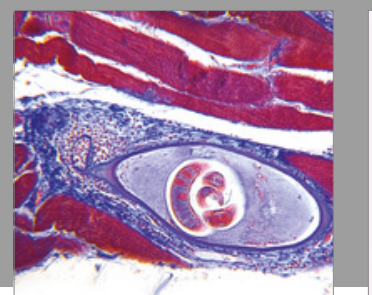

Gastroenterology Research and Practice
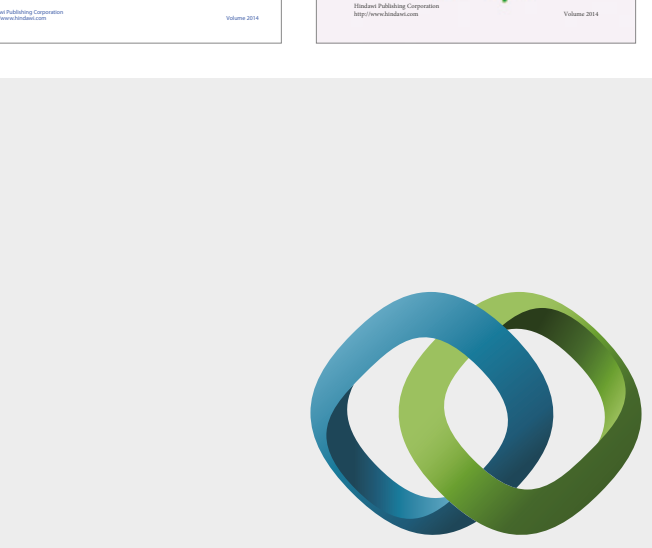

\section{Hindawi}

Submit your manuscripts at

https://www.hindawi.com
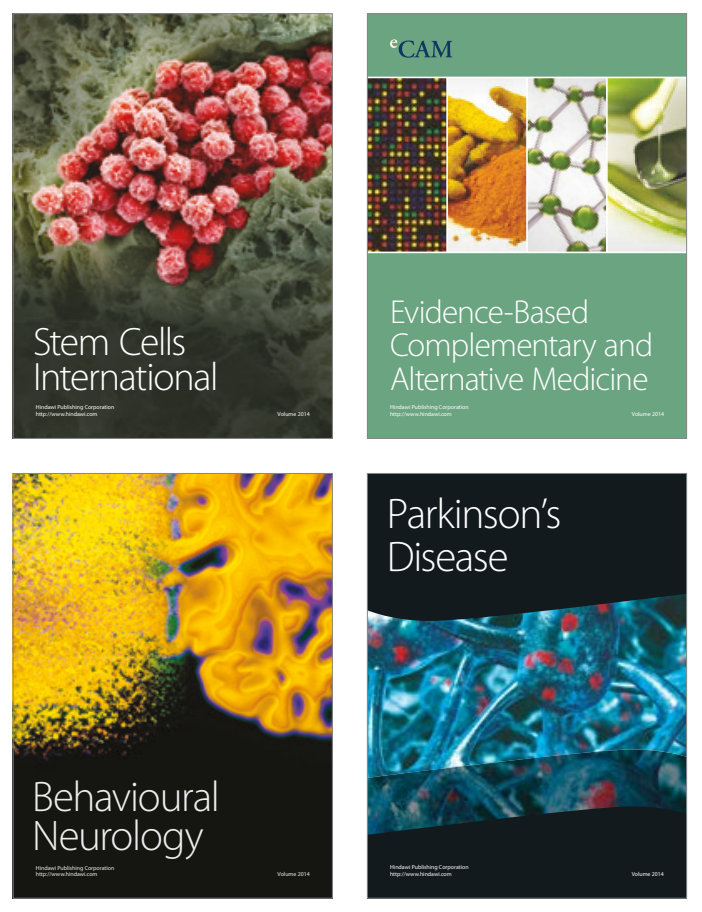
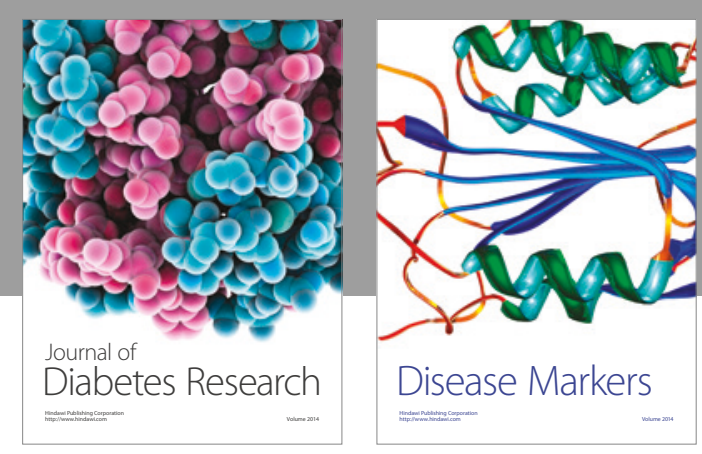

Disease Markers
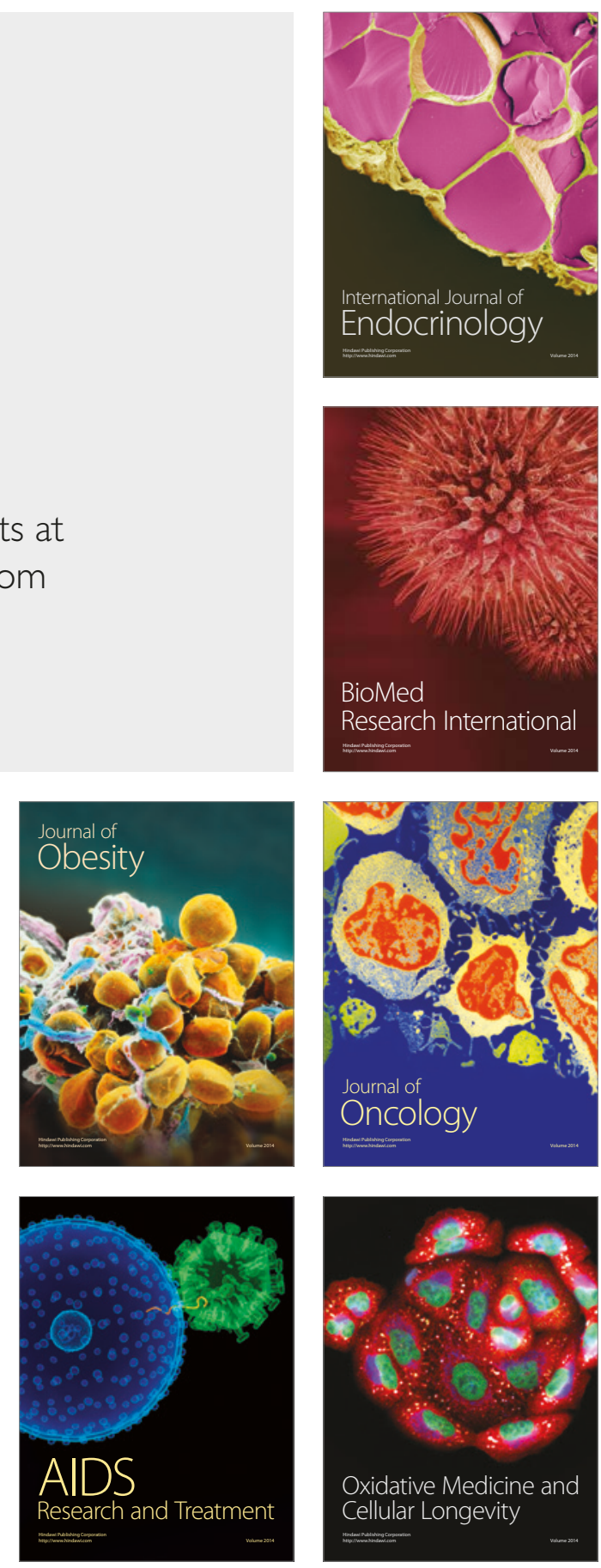